\title{
Comparison of clinical performance of i-gel with laryngeal mask airway pro-seal in elective surgery in adults
}

\author{
SG Curpod ${ }^{*}$, S Basavalingaiah ${ }^{2}$ \\ Associate Professor of Anaesthesia ${ }^{I}$, Junior Resident ${ }^{2}$, ESIC - Medical College and PGIMSR, \\ Karnataka, India.
}

Corresponding author: prasad_cgs@yahoo.co.in

\begin{abstract}
Aim: The present study was performed to compare the clinical performance of i-gel and PLMA in terms of the efficacy and safety management in anaesthetized adult patients undergoing elective surgery.

Materials and Methods: 80 patients of either sex were randomized in two groups. Group I $(n=40)$ for i-gel and Group P $(n=40)$ for Proseal. After induction i-gel or Proseal was inserted. The cuff of PLMA inflated and pressure maintained at $60 \mathrm{cmH}_{2} \mathrm{O}$. Insertion time, ease and number of attempts at insertion, airway sealing pressure, airway sealing quality score (ASQS), fiberoptic assessment, ease and number of attempts at gastric tube placement and complications during insertion, maintenance and removal were noted. Statistical analysis was done using Statistical Package for Social Science (SPSS) 20, the sample size was calculated with $99 \%$ power $(\beta$ error $=1 \%), 95 \%$ confidence $(\alpha$ error $=5 \%)$, $\mathrm{p}<0.05$ was considered statistically significant.

Results: Demographic data were comparable. Mean insertion time for i-gel (12.30 \pm $1.018 \mathrm{sec})$ was significantly lower than PLMA $(13.82 \pm 1.083 \mathrm{sec}):(\mathrm{p}<0.00)$, i-gel was easier to insert $(\mathrm{p}<0.010)$ and number of attempts were comparable $(\mathrm{p}<0.644)$. Airway sealing pressure $\left(\mathrm{cmH}_{2} \mathrm{O}\right)$ was significantly lower in group-I $(23.925 \pm 0.729$ vs $29 \pm 0.751$, $\mathrm{p}=0.000)$. ASQS were comparable ( $\mathrm{p}<0.762) .37(92.5 \%), 3(7.5 \%)$ and $30(75 \%), 10$ $(25 \%)$ patients had fiberoptic score of $1 / 2$ in i-gel and PLMA respectively $(\mathrm{p}<0.034)$. Gastric tube placement, haemodynamic parameters and complications were comparable.
\end{abstract}

Conclusion: i-gel is an effective and safe alternative supraglottic airway device.

Keywords: i-gel; LMA-Proseal; supraglottic airway devices

\section{Introduction}

Introduction of Supraglottic airway devices (SAD) has revolutionized the airway management. The first successful supraglottic airway device, the Laryngeal Mask Airway (LMA)-Classic, became available in 1989. Since then the indications for the LMA have evolved rapidly and there is now a far more liberal attitude to indications for laryngeal mask use. It is estimated that over 200 million anaesthetics have now been administered using c-LMA. The constant evolution in device design has encouraged to introduction of various other SADs like ProSeal LMA, Intubating LMA and i-gel to overcome the limitations of c-LMA. ${ }^{1}$

The risk of aspiration with c-LMA is reported to be around $6 \%-9 \%$, as detected by observations of the oesophagus via fiberoptic bronchoscopy
(FOB), or low pulmonary compliance. ${ }^{2}[($ e.g. obesity) requiring peak inspiratory pressure greater than $20 \mathrm{cmH}_{2} 0$ ] LMA ProSeal (PLMA) was introduced in 2000 to improve performance during controlled ventilation, safety regarding aspiration, and an ability to diagnose misplacement of the device tip. However, both the c-LMA and PLMA have cuff related complications. High cuff pressure in laryngeal mask airways can cause damage to the mucosae on periglottic and supraglottic structures and associated with increased morbidity, such as sore throat, hoarseness of voice and nerve palsies. ${ }^{3}$

Therefore to overcome the limitations of PLMA a new and cheaper SAD called i-gel was developed. i-gel is a novel and innovative, latex free supraglottic device, made up of medical grade thermoplastic elastomer, which is soft, gel

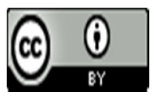

(C) 2017. Curpod et al. This is an Open Access article distributed under the terms of the Creative Commons Attribution License (http: //creativecommons.org/licenses/by/4. 0), which permits unrestricted use, distribution, and reproduction in any medium, provided the original work is properly credited 
like, transparent and designed to anatomically fit the perilaryngeal and hypo pharyngeal structures with a non inflatable cuff and a channel for gastric suction catheter placement. $^{4}$ The potential advantages of the i-gel are that it is compatible with anatomical structures, it can be easily inserted into the mouth, and there is reduced risk of pharyngeal tissue compression due to lack of high cuff pressure. ${ }^{5}$

This study was done to compare the insertion time, ease of insertion, insertion attempts, the airway sealing pressure, airway sealing quality score, fiberoptic assessment, ease of gastric tube placement and complications between i-gel and LMA- pro seal.

\section{Material and methods}

The prospective randomized study was conducted after obtaining approval of the hospital ethical committee and written informed consent from the patients from November 2013 to May 2015. The study was conducted on 80 patients, 40 in each group undergoing elective surgery in supine position under general anaesthesia with controlled ventilation with the following inclusion criteria, ASA class 1-2, age 20-60years of either sex posted for elective surgical procedures of duration of $1-1 \frac{1}{2}$ hours with no requirement for endotracheal intubation. Patient with risk factors for difficult airway (mouth opening of $<2 \mathrm{~cm}$, Mallampati class 4 , limited neck extension, history of previous difficult intubation), known pulmonary and cardiovascular diseases, risk of aspiration (full stomach, hiatus hernia, gastroesophageal reflex disease, emergency surgery) were excluded from the study.

Following detailed pre-anaesthetic checkup, informed written consent was obtained from patient fulfilling the above required criteria. Patients were randomly allocated into two groups namely group I (i-gel, $n=40$ ) and group P (PLMA, $\mathrm{n}=40$ ) in a sealed envelope. All patients were asked to fast overnight. On the day of surgery, $18 \mathrm{~g}$ vasofix was inserted and preloaded with $500 \mathrm{ml}$ of Ringer Lactate solution. ECG, NIBP, $\mathrm{SpO}_{2}$ monitors were connected and baseline readings noted. Midazolam $1 \mathrm{mg}$, glycopyrrolate $0.2 \mathrm{mg}$, ranitidine $50 \mathrm{mg}$ and ondansetron $4 \mathrm{mg}$ intravenously was given to all the patients. All patients were preoxygenated for three minutes and anaesthesia was induced with propofol $2 \mathrm{mg} / \mathrm{kg}$ and fentanyl $2 \mathrm{mcg} / \mathrm{kg}$. Neuromuscular blockade was achieved with veccuronium bromide $0.1 \mathrm{mg} / \mathrm{kg}$, and ventilated with oxygen, nitrous oxide and sevoflurane. Once adequate depth was achieved, i-gel or PLMA lubricated with soluble jelly was inserted. The cuff of PLMA was inflated with air and an effective airway was confirmed by bilateral symmetrical chest expansion on manual ventilation, square waveform on capnography, stable oxygen saturation, no audible leak of the gases and lack of gastric insufflation. Intracuff pressure of PLMA was set at $60 \mathrm{cmH}_{2} \mathrm{O}$ throughout anaesthesia using a manometer. The device was fixed over the chin. Anaesthesia was maintained with oxygen, nitrous oxide and sevoflurane and ventilated with intermittent positive pressure ventilation. A lubricated gastric tube was placed in the stomach through the gastric channel. Haemodynamic parameters were monitored prior to insertion of the device and then at 5,10 and 15 mins after insertion of the device. Thereafter monitoring was done every $15 \mathrm{mins}$ till the end of the surgery.

Insertion time was noted as the time interval between picking up the device and securing an effective airway as recorded by an independent observer. The ease of insertion of device was assessed using a subjective scale of 1-4 (1-no resistance, 2- mild resistance, 3-moderate resistance, 4- inability to place a device). Failure of a device was identified as three unsuccessful insertion attempts or inadequate ventilation. Such patients were withdrawn from the study and insertion was recorded as failure and a cuffed endotracheal tube was inserted.

The Airway Sealing Pressure (ASP) was measured at cuff pressure of $60 \mathrm{cmH}_{2} \mathrm{O}$ (in case of PLMA) by closing the expiratory valve of the circle system at a fixed gas flow of $3 \mathrm{~L} / \mathrm{min}$ and recording the airway pressure at which equilibrium was reached. At this stage an audible leak at the mouth (sound of gas escaping from mouth heard by listening close to patient's mouth) and the stomach (sound of gas escaping into oesophagus heard by auscultation over epigastrium) was ascertained. Tidal volume loss was detected by inspiratory (set) - expiratory (outcome) volume on the ventilator display

(C) 2017. Curpod et al. This is an Open Access article distributed under the terms of the Creative Commons Attribution License (http: //creativecommons.org/licenses/by/4. 0), which permits unrestricted use, distribution, and reproduction in any medium, provided the original work is properly credited 
screen. Airway seal was scored using Airway Sealing Quality Score (ASQS) as per Table 1.

Table 1: Airway sealing quality score ${ }^{10}$

\begin{tabular}{|l|l|}
\hline 1 & No leak detected \\
\hline 2 & Minor leak of tidal volume (Vt loss <20\%) \\
\hline 3 & $\begin{array}{l}\text { Moderate leak of tidal volume (Vt loss 20\% - } \\
40 \%)\end{array}$ \\
\hline 4 & Insufficient seal (Vt loss $>40 \%)$ \\
\hline
\end{tabular}

The anatomical position of the device was assessed by introducing a flexible fiberoptic bronchoscope into the airway tube to a position proximal to the terminal end. The scoring of fiberoptic examination was done by using fiberoptic scoring system as per Table 2 .

Table 2: Fiber optic scoring system ${ }^{6-8}$

\begin{tabular}{|l|l|}
\hline 1 & Clear view of vocal cords \\
\hline 2 & Only arytenoid cartilages visible \\
\hline 3 & Only epiglottis visible \\
\hline 4 & No laryngeal structures visible \\
\hline
\end{tabular}

Ease of placement of gastric tube was recorded as either: easy/difficult/failure. Failure was defined as inability to advance the orogastric tube into the stomach within two attempts. Its correct placement confirmed by injection of air and auscultation over the epigastrium or aspiration of gastric contents. At the end of surgical procedure anaesthesia was discontinued and patient reversed with standard dose of neostigmine and glycopyrrolate and device removed. Complications occurring during insertion, maintenance and removal were noted for each patient. Bronchospasm or laryngospasm, blood staining of tongue, lip and dental trauma, regurgitation and aspiration of gastric contents were evaluated by examining oropharyngeal structures by light source and treated appropriately. Blood staining of the SAD were recorded during removal. Postoperatively patients were questioned for sore throat, dysphagia, dyspnea, hoarseness of voice.

\section{Statistics}

In the present study to calculate the sample size, with $99 \%$ power $(\beta$ error $=1 \%), 95 \%$ confidence $(\alpha$ error $=5 \%)$ and to minimum detectable difference between the groups as $3.93 \mathrm{sec}$ with $2.91 \mathrm{SD}$ required a minimum of 21 subjects. ${ }^{10}$ Statistical analysis was done using
Statistical Package for Social Science (SPSS) 20. The various appropriate descriptive and inferential statistics had been calculated for the numeric data like age, height, weight, heart rate, $\mathrm{SBP}, \mathrm{DBP}, \mathrm{SpO}_{2}$ etc. Mean and standard deviations (SD) were calculated for numeric data and expressed as mean $\pm \mathrm{SD}$. And for nonnumeric data frequency and percentages were calculated.

In order to compare the mean values of two groups (I and P), two tailed unpaired t-test was used and Chi square test was used for association between two attributes like ease of insertion, number of attempts, airway sealing quality score, fiberoptic score, ease and number of attempts of gastric tube insertion, complications etc in both the groups. P value < 0.05 had been considered as significant value.

\section{Results}

Table 3: Patient demographic characteristics (Mean \pm SD)

\begin{tabular}{|c|c|c|c|}
\hline & Group I & Group P & $\begin{array}{l}\mathrm{p}- \\
\text { value }\end{array}$ \\
\hline Age (Years) & $33.80 \pm 9.202$ & $32.00 \pm 10.115$ & 0.408 \\
\hline $\operatorname{Sex}(M / F)$ & $20 / 20$ & $23 / 17$ & 0.501 \\
\hline Weight(kgs) & $60.48 \pm 8.635$ & $59.85 \pm 8.267$ & 0.742 \\
\hline Height $(\mathrm{cms})$ & $155 \pm 4.14$ & $154.85 \pm 4.897$ & 0.886 \\
\hline \multicolumn{4}{|c|}{ Type of surgical procedures } \\
\hline $\begin{array}{l}\text { General } \\
\text { Surgery }\end{array}$ & $17(42.5 \%)$ & $13(32.5 \%)$ & \multirow{3}{*}{0.449} \\
\hline $\begin{array}{l}\text { Plastic } \\
\text { Surgery }\end{array}$ & $6(15 \%)$ & $8(20 \%)$ & \\
\hline Orthopaedics & $17(42.5)$ & $19(47.5 \%)$ & \\
\hline
\end{tabular}

There was no difference between the two groups with respect to demographic and surgical details (Table 3). In all the patients the i-gel or PLMA was inserted within two attempts. The mean insertion time for I-gel was $12.30 \pm 1.018$ seconds and PLMA was $13.82 \pm 1.083$ seconds. It was comparable between the two groups. ( $\mathrm{p}=0.00$, Table 4). With regards to ease of insertion a significant difference $(\mathrm{p}=0.010)$ was found between i gel and PLMA. In group I, 35 (87.5\%) and $5(12.5 \%)$ patients and in Group P, 25 $(62.5 \%)$ and $15(37.5 \%)$ patients had a scale of 1 and 2 respectively (Table 4 ). In all the patients the device was inserted successfully within two attempts. The first attempt success rate was high

(C) 2017. Curpod et al. This is an Open Access article distributed under the terms of the Creative Commons Attribution License (http: //creativecommons.org/licenses/by/4. 0), which permits unrestricted use, distribution, and reproduction in any medium, provided the original work is properly credited 
for both groups. [38 (95\%) for Group I and 37 (92.5\%) for Group P, p = 0.644, Table 4]

Table 4: Insertion characteristics

\begin{tabular}{|l|l|l|l|}
\hline & $\begin{array}{l}\text { Group } \\
\text { I }\end{array}$ & Group P & $\mathrm{p}$-Value \\
\hline $\begin{array}{l}\text { Insertion } \\
\text { time(sec) }\end{array}$ & $12.30 \pm 1.018$ & $\begin{array}{l}13.82 \pm \\
1.083\end{array}$ & 0.00 \\
\hline $\begin{array}{l}\text { Ease of } \\
\text { insertion } \\
1\end{array}$ & $35(87.5 \%)$ & $\begin{array}{l}25(62.5 \%) \\
15(37.5 \%)\end{array}$ & 0.010 \\
2 & 5 & 0 & \\
3 & $(12.5 \%)$ & 0 & \\
4 & 0 & & \\
\hline $\begin{array}{l}\text { No of } \\
\text { attempts }\end{array}$ & $38(95 \%)$ & $37(92.5 \%)$ & 0.644 \\
1 & $2(5 \%)$ & $3(7.5 \%)$ & \\
2 & 0 & $29 \pm 0.751$ & 0.000 \\
\hline ASP (cm & $23.925 \pm$ & & \\
$\left.\mathrm{H}_{2} \mathrm{O}\right)$ & 0.729 & $34(85 \%)$ & \\
\hline $\begin{array}{l}\text { ASQS } \\
1\end{array}$ & $33(82.5 \%)$ & $6(15 \%)$ & 0.762 \\
2 & $7(17.5 \%)$ & 0 & \\
3 & 0 & 0 & \\
4 & 0 & $30(75 \%)$ & \\
\hline $\begin{array}{l}\text { Fiberoptic } \\
\text { score }\end{array}$ & $37(92.5 \%)$ & $10(25 \%)$ & 0.034 \\
2 & $3(7.5 \%)$ & 0 & \\
3 & 0 & 0 & \\
4 & 0 & & \\
\hline
\end{tabular}

Table 5: Comparison of other parameters

\begin{tabular}{|c|c|c|c|}
\hline & $\begin{array}{l}\text { Group } \\
\text { I }\end{array}$ & Group P & p-Value \\
\hline \multicolumn{4}{|c|}{ Gastric tube insertion } \\
\hline $\begin{array}{l}\text { Ease } \\
\text { Easy } \\
\text { Difficult } \\
\text { Failed }\end{array}$ & $\begin{array}{l}36(90 \%) \\
4(10 \%) \\
0\end{array}$ & $\begin{array}{l}34(85 \%) \\
5 \quad(12.5 \%) \\
1(2.5 \%)\end{array}$ & 0.723 \\
\hline $\begin{array}{l}\text { Attempts } \\
1 \\
2\end{array}$ & $\begin{array}{l}38(95 \%) \\
2(5 \%)\end{array}$ & $\begin{array}{l}34(87.2 \%) \\
5(12.8 \%)\end{array}$ & 0.285 \\
\hline $\begin{array}{l}\text { No. of patients } \\
\text { with } \\
\text { complications } \\
\text { No. of patients } \\
\text { without } \\
\text { complications }\end{array}$ & $\begin{array}{l}3(7.5 \%) \\
37(92.5 \%)\end{array}$ & $\begin{array}{l}5(12.5 \%) \\
35(87.5 \%)\end{array}$ & 0.456 \\
\hline
\end{tabular}

The average sealing pressure in Group I was $23.925 \pm 0.729 \mathrm{~cm} \mathrm{H}_{2} \mathrm{O}$ and in Group $\mathrm{P}$ was $29 \pm$ $0.751 \mathrm{~cm}_{2} \mathrm{O}$, with a p value of 0.000 which was significant (Table 4). Adequate ventilation was achieved in both the groups. Airway sealing quality score as determined by percentage loss of delivered tidal volume were comparable between two groups. (Group I $33(82.5 \%)$ and $7(17.5 \%)$ patients and Group P $34(85 \%)$ and $6(15 \%), \mathrm{p}=$ 0.762 , Table 4)

The i-gel group provided a better fiberoptic view of glottis than proseal LMA. In Group-I 37 (92.5\%) and $3(7.5 \%)$ patients and in Group P 30 $(75 \%)$ and $10(25 \%)$ patients had fiberoptic score of 1 and 2 respectively with a $p$ value of 0.034 which was statistically significant (Table 4). Gastric tube was inserted in all the patients except one patient in Group P. There was no statistically significant difference regarding the ease and attempts of gastric tube insertion between the two groups (Table 5). There was no statistically significant difference between the two groups with regards to complications (Table 5).

\section{Discussion}

Our study demonstrated that i-gel and PLMA are equally effective supraglottic airway devices. But i-gel scores over PLMA regarding ease of insertion, airway sealing pressure and good fiberoptic view providing effective anatomical conformity.

Shorter insertion time influence the feasibility of supraglottic devices. Many studies have reported shorter insertion time for i-gel compared to other supraglottic devices because of less flexible stem and no need for cuff inflation. ${ }^{9}$ Statistically significant shorter mean insertion time observed in our study correlates with the results of studies of Chauhan et al and Tokgoz et al. ${ }^{10,11}$ Sharma B et al found shorter mean insertion time for PLMA when compared to i gel but it was not statistically significant. ${ }^{12}$ But these differences in time interval are clinically not significant.

The ease of insertion is better with i-gel than PLMA. Levitan and Kinkle presumed that on insertion of LMA, the deflated leading edge of the mask can catch the edge of the epiglottis and cause it to downfold or impede proper placement beneath the tongue. ${ }^{5}$ Brimacombe et al presumed that the difficulties in inserting LMA-ProSeal were caused by larger cuff impeding digital intraoral positioning and propulsion into the pharynx, the lack of back plate making cuff more likely to

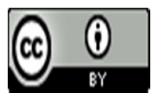

(C) 2017. Curpod et al. This is an Open Access article distributed under the terms of the Creative Commons Attribution License (http: //creativecommons.org/licenses/by/4. 0), which permits unrestricted use, distribution, and reproduction in any medium, provided the original work is properly credited 
fold over at the back of mouth and the need for more precise tip positioning to prevent air leaks up the drainage tube. ${ }^{13,14}$ Chauhan et al and Singh et al observed the ease of insertion was better with i-gel than PLMA. Chauhan et al also observed that number of manipulations required were more in PLMA resulting in haemodynamic changes. ${ }^{10,15}$

In our study the device was inserted successfully in all patients. Insertion attempts of i-gel vs PLMA were not statistically significant. Other studies comparing i-gel and Proseal LMA found similar results. Tokgoz et al has found a high success rate at first attempt and overall success in i-gel when compared to PLMA. ${ }^{11,15,16}$

Airway sealing pressure is used to monitor the quality of airway seal, which prevents gastric insufflation, aspiration and oropharyngeal air leakage. The seal pressure appears to improve over time in number of patients due to thermoplastic properties of the gel cuff, which may form a more efficient seal around the larynx after warming to body temperature. Effective airway leakage pressure is important to provide adequate ventilation in patient with increased airway resistance. ${ }^{17}$ Similar to our result, significant lower mean airway sealing pressure with i-gel were observed by Chauhan et al, Tokgoz et al and Singh et al. But there was no statistically significant difference in Airway Sealing Quality Score. i-gel thus provides effective seal and ventilation at relatively lower airway pressures when compared to PLMA which requires higher airway pressures to provide effective seal and ventilation.

In many studies the placement of supraglottic device were confirmed by fiberoptic bronchoscope, has showed that i-gel consistently achieves proper positioning and effectively conforms to the perilaryngeal airway. ${ }^{10,11}$ The fiber optic image score depends on hypo pharyngeal device position and folding of epiglottis. Chauhan et al noted i-gel had an excellent anatomical fit (Grade 1 view $=97.5 \%$ ) which was significantly better than the PLMA (Grade 1 view $=75 \%$ ). Tokgoz et al observed a notably good view of vocal cords in i-gel.
There was no significant statistical difference regarding the ease of placement of gastric tube and number of attempts. Similar results are also found in many studies..$^{10,11,15}$ In our study we did not experience any complications during insertion and maintenance. None of the patients in both the groups had postoperatively sore throat, dysphagia, dyspnea, hoarseness of voice. Many studies have recorded the incidence of blood staining of the device, tongue, lip and dental trauma as more with other supraglottic devices. ${ }^{18,19}$ Devices with inflatable mask have the potential to cause tissue distortion, venous compression and nerve injury, which explains the high incidence of associated postoperative morbidity. ${ }^{5}$

To conclude the i-gel is comparable to PLMA in securing the airway during controlled ventilation. It is better than PLMA in terms of ease of insertion, with less airway sealing pressure providing better ventilation and effectively conforming to the perilaryngeal anatomy, despite the lack of an inflatable cuff.

\section{References}

1. Dorsch JA, Dorsch SE. Supraglottic airway devices. Understanding Anaesthesia Equipment. 5th edition: Lippincott Williams and Wilkins;2008:461-519.

2. Barker P, Langton JA, Murphy PJ, Rowbotham DJ. Regurgitation of gastric contents during general anaesthesia using the laryngeal mask airway.BrJAnaesth1992;69:314-15.

https://doi.org/10.1093/bja/69.3.314 PMid: 1389850

3. Wong JG, Heaney M, Chambers NA, Erb TO, von Ungern- Sternberg BS. Impact of laryngeal mask airway cuff pressures on the incidence of sore throat in children. Paediatr Anaesth 2009; 19(5):464-69. https://doi.org/10.1111/j.1460-9592.2009.02968.x PMid:19281479.

4. I-gel User guide: Intersurgical Ltd; 2009 [Internet]. Available from: http://www.i-gel.com.

5. Levitan RM, Kinkle WC. Initial anatomic investigations of the I-gel airway: a novel supraglottic airway without inflatable cuff. Anaesthesia 2005;60:1022-26. https://doi.org/10.1111/j.1365-2044.2005.04258.x PMid:16179048

(C) 2017. Curpod et al. This is an Open Access article distributed under the terms of the Creative Commons Attribution License (http: //creativecommons.org/licenses/by/4. 0), which permits unrestricted use, distribution, and reproduction in any medium, provided the original work is properly credited 
6. Brimacombe J, Berry A. A proposed fiberoptic scoring system to standardize the assessment of laryngeal mask airway position. Anesth Analg 1993;76:457

PMid:8424538

7. Brimacombe J, Puhringer F. A fiberoptic scoring system to assess the position of laryngeal mask devices. Inter observer variability and a comparison between the standard, flexible and intubating laryngeal mask airway. Anasthesiol intensivemed Notfallmed Schmerzther 2000;35:692-4

https://doi.org/10.1055/s-2000-8164

PMid:11130130

8. Ovasapian A, Klock PA Jr, Chalabi BT. Proseal laryngeal mask airway. Fiberoptic assessment of the device position and utility. Anesthesiology 2002;96:A-1321.

https://doi.org/10.1097/00000542-200209002$\underline{01321}$

9. Lee JR, Kim MS, Kim JT et al. A randomised trial comparing the I-gel ${ }^{\mathrm{TM}}$ with the LMA Classic ${ }^{\mathrm{TM}}$ in children.Anaesthesia2012;67:606-11.

https://doi.org/10.1111/j.1365-2044.2012.07072.x PMid:22352745

10. Chauhan G, Nayar P, Seth A et al. Comparison of clinical performance of the I-gel with LMA Proseal. Journal of anaesthesiology and clinical pharmacology 2013;29(1):56-60.

https://doi.org/10.4103/0970-9185.105798 PMid:23493414 PMCid:PMC3590543

11. Tokgoz O, Tufek A, Beyaz SG et al. Comparison of the efficacies of I-gel ${ }^{\mathrm{TM}}$ and LMA-ProSeal ${ }^{\mathrm{TM}}$ for airway management in pediatric patients. Turkish Journal of Medical Sciences 2013;43:208-13.

12. Sharma B, Sehgal R, Sahai C, Sood J. PLMA vs. Igel: A comparative Evaluation of Respiratory Mechanics in Laparoscopic Cholecystectomy. J of Clin Pharmacol 2010;26(4):451-57.

13. Brimacombe J, Keller C. The ProSeal laryngeal mask air- way: a randomized, crossover study with the standard laryngeal mask airway in paralyzed, anesthetized patients. Anesthesiology 2000;93:104-9.

https://doi.org/10.1097/00000542-200007000-

$\underline{00019}$

PMid:10861152

14. Brimacombe J, Keller C, Fullekrug B, et al. A multicenter study comparing the ProSeal and Classic laryngeal mask airway in anesthetized, non paralyzed patients. Anesthesiology 2002;96:28995.

https://doi.org/10.1097/00000542-200202000-

$\underline{00011}$

PMid:11818758

15. Singh I, Gupta M, Tandon M. Comparison of Clinical Performance of $\mathrm{I}_{-} \mathrm{Gel}^{\mathrm{TM}}$ with LMAProseal $^{\mathrm{TM}}$ in Elective Surgeries. Indian Journal of Anaesthesia2009;53(3):302-5.

PMid:20640137 PMCid:PMC2900120

16. Gasteiger L, Brimacombe J, Perkhofer D, et al. Comparison of guided insertion of the LMA Proseal $^{\mathrm{TM}}$ vs the i-gel ${ }^{\mathrm{TM}}$. Journal of Association of Anaesthetists of Great Britain and Ireland 2010;65:913-16.

17. Francksen $H$, Renner $J$, Hanss $R$, et al. A comparison of the I-gel with the LMA-Unique in non- paralysed anaesthetised adult patients. Anaesthesia2009;64:1118-24. https://doi.org/10.1111/j.1365-2044.2009.06017.x PMid:19735404

18. Keller C, Puhringer F, Brimacombe JR. The influence of cuff volumes on oropharyngeal leak pressure and fiberoptic position with the laryngeal mask airway. $\mathrm{Br} \mathrm{J}$ Anaesth 1998;81:186-87. https://doi.org/10.1093/bja/81.2.186

PMid:9813520

19. Brimacombe J, Holyoake L, Keller C, et al. Pharyngolaryngeal, neck and jaw discomfort after anaesthesia with the face mask and laryngeal mask airway at high and low cuff volumes in males and female.Anesthesiology2000;93:26-31. https://doi.org/10.1097/00000542-200007000$\underline{00009}$

PMid:10861142

(C) 2017. Curpod et al. This is an Open Access article distributed under the terms of the Creative Commons Attribution License (http: //creativecommons.org/licenses/by/4. 0), which permits unrestricted use, distribution, and reproduction in any medium, provided the original work is properly credited 